\title{
Design of a SIW Bandpass Filter Using Defected Ground Structure with CSRRs
}

\author{
Weiping Li, ${ }^{1,2}$ Zongxi Tang, ${ }^{1}$ and Xin Cao ${ }^{1}$ \\ ${ }^{1}$ School of Electronic Engineering, University of Electronic Science and Technology of China, No. 2006, Xiyuan Ave., \\ West Hi-Tech Zone, Chengdu 611731, China \\ ${ }^{2}$ School of Information Engineering, East China Jiaotong University, No. 88, Shuanggang Road, Nanchang 330013, China \\ Correspondence should be addressed to Weiping Li; lwp8277@126.com
}

Received 20 October 2016; Revised 28 December 2016; Accepted 10 January 2017; Published 29 January 2017

Academic Editor: Guangya Zhou

Copyright (C) 2017 Weiping Li et al. This is an open access article distributed under the Creative Commons Attribution License, which permits unrestricted use, distribution, and reproduction in any medium, provided the original work is properly cited.

In this paper, a substrate integrated waveguide (SIW) bandpass filter using defected ground structure (DGS) with complementary split ring resonators (CSRRs) is proposed. By using the unique resonant properties of CSRRs and DGSs, two passbands with a transmission zero in the middle have been achieved. The resonant modes of the two passbands are different and the bandwidth of the second passband is much wider than that of the first one. In order to increase out-of-band rejection, a pair of dumbbell DGSs has been added on each side of the CSRRs. The structure is analyzed using equivalent circuit models and simulated based on EM simulation software. For validation, the proposed filter is fabricated and measured. The measurement results are in good agreement with the simulated ones.

\section{Introduction}

Substrate integrated waveguide (SIW) was first proposed in 2003 [1]. Based on the $\mathrm{TE}_{n 0}$ transmission mode, SIW replaces the side metallic walls of the rectangular waveguide with two rows of metallic via holes, which converts conventional waveguides into planar structures [2-4]. Therefore, SIWs not only have the properties of high quality factor and low radiation loss which are similar to metallic waveguides but also have the prominent advantage of compact size due to their planar physical structure. SIWs have been applied to the design of filters, oscillators, power dividers, couplers, and many other microwave components. Complementary split ring resonator (CSRR) was proposed in 2004 as a 3D metamaterial [5] that can exhibit negative permeability near its resonant frequency and therefore can be considered as a composite right/left handed (CRLH) structure. When CSRRs are employed in SIW, passbands based on the evanescent mode below the cutoff frequency of the SIW can be created [6, 7], which can further miniaturize the size of SIW microwave devices. As for the defected ground structure (DGS), it can be regarded as "electromagnetic bandgap" (EBG) structure in the microwave region $[8,9]$ and the structure is realized by etching periodic or nonperiodic patterns on the metallic layer in order to create extra transmission zeros. When the DGS is employed in filter design, the out-of-band rejection can be improved without major influence on the insertion loss of the passbands [10].

Based on the three different structures mentioned above, in this paper, a novel dual-band bandpass filter with much compact size and wider passbands is proposed by combining these structures together. Due to the unique resonant properties, two different resonant modes have been achieved to form the passbands and a transmission zero is generated between the two passbands. The corresponding equivalent circuit has been analyzed and the results of full-wave simulation and experimental measurement have been presented.

\section{Theory and Analysis}

As shown in Figure 1, a SIW consists of three layers, namely, a copper plane, a substrate layer, and a ground plane. Metallic via holes are etched at the edge in parallel position. For a SIW resonant cavity, at $\mathrm{TE}_{m 0 n}$ mode, the resonant frequency can be calculated as

$$
f_{m 0 n}=\frac{c_{0}}{2 \sqrt{\varepsilon_{r}}} \sqrt{\left(\frac{m}{a}\right)^{2}+\left(\frac{n}{l}\right)^{2}}
$$




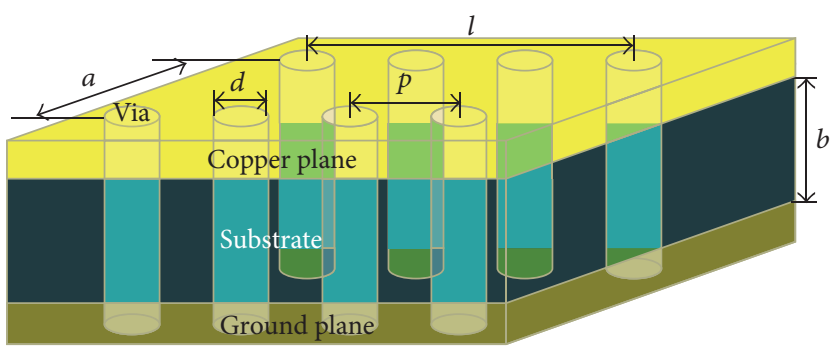

Figure 1: The 3D view of an SIW.

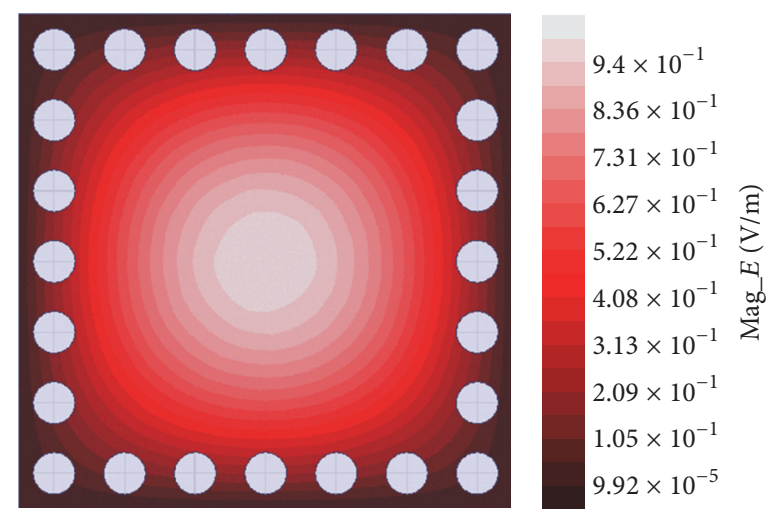

FIgURE 2: The field distribution at $\mathrm{TE}_{101}$ resonant mode.

where $c_{0}$ is the speed of electromagnetic waves in vacuum and $\varepsilon_{r}$ is the relative dielectric constant. For SIW cavities, $\mathrm{TE}_{101}$ is the dominant mode, and its corresponding resonant frequency $f_{101}$ can be given as

$$
f_{101}=\frac{c_{0}}{2 \sqrt{\varepsilon_{r}}} \sqrt{\left(\frac{1}{a}\right)^{2}+\left(\frac{1}{l}\right)^{2}} .
$$

The field distribution at $\mathrm{TE}_{101}$ resonant mode is depicted in Figure 2. The electromagnetic energy distributes mainly at the center of the SIW cavity. Therefore, radiation loss can be suppressed and, in this way, the quality factor can be improved. By comparing with conventional microstrip resonators, the insertion loss is reduced and better transmission performance is obtained.

The physical structure of CSRRs is depicted in Figure 3(a). The blue part is metal and the yellow part is the etched CSRRs. They consist of two split resonant rings, and the smaller one is inside the larger one with their openings opposite to each other. While working near the resonant frequency, CSRRs behave like a pair of electric dipoles when they are excited under a vertical axial electric field excitation. Therefore, CSRRs can be regarded as $L C$ parallel circuit, as shown in Figure 3(b), where $C_{r}$ and $L_{r}$ represent the self capacitance of the rings and their mutual inductance, respectively; the values of them can be calculated as

$$
\begin{aligned}
& C_{r}=\left(4 l_{\text {out }}-g_{\text {out }}\right) C_{\text {out }}+\left(4 l_{\text {in }}-g_{\text {in }}\right) C_{\text {in }}, \\
& L_{r}=\left(4 l_{\text {out }}-g_{\text {out }}\right) L_{\text {out }}+\left(4 l_{\text {in }}-g_{\text {in }}\right) L_{\text {in }},
\end{aligned}
$$

where $C_{\text {out }}$ and $L_{\text {out }}$ are the unit characteristic capacitance and inductance of the outside ring, while $C_{\text {in }}$ and $L_{\text {in }}$ are the unit characteristic capacitance and inductance of the inside ring. Then, the resonant frequency of the CSRRs can be calculated as

$$
f_{\mathrm{CSRR}}=\frac{1}{2 \pi \sqrt{L_{r} C_{r}}} .
$$

When CSRRs are employed in SIW, a passband with the evanescent resonant mode below the cutoff frequency of the SIW can be created because CSRRs work as electric dipoles. Therefore, CSRRs can be used to miniaturize the size of the conventional SIWs. In order to increase the out-of-band rejection, defected ground structure (DGS) can be applied in the SIW. The physical structure of the dumbbell DGS is shown in Figure 4(a). The bottom metal layer is etched into " $\mathrm{H}$ " shape and this structure can prevent electromagnetic wave from propagating in the transmission line at a certain frequency point, and thus a transmission zero (TZ) can be created (shown in Figure 5). The equivalent circuit of the DGS is shown in Figure 4(b), and if the TZ is designed properly, it can be employed to increase the out-of-band rejection in filters. The circuit elements $L_{d}$ and $C_{d}$ can be calculated as

$$
\begin{aligned}
C_{d} & =\frac{5 f_{c}}{\pi\left(f_{0}^{2}-f_{c}^{2}\right)}, \\
L_{d} & =\frac{250}{\pi^{2} f_{0}^{2} C_{d}},
\end{aligned}
$$

where $f_{c}$ and $f_{0}$ are the cutoff frequency and resonance frequency of the stopband, respectively. 


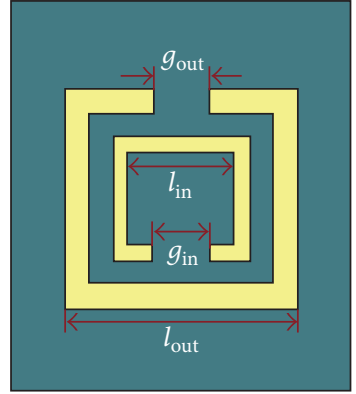

(a)

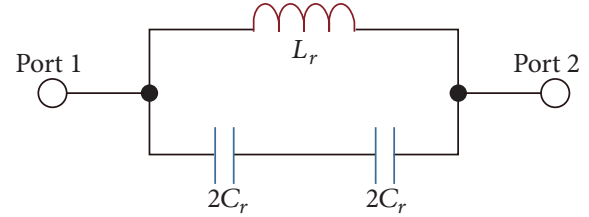

(b)

FIgURE 3: The physical structure (a) and the equivalent circuit (b) of CSRRs.

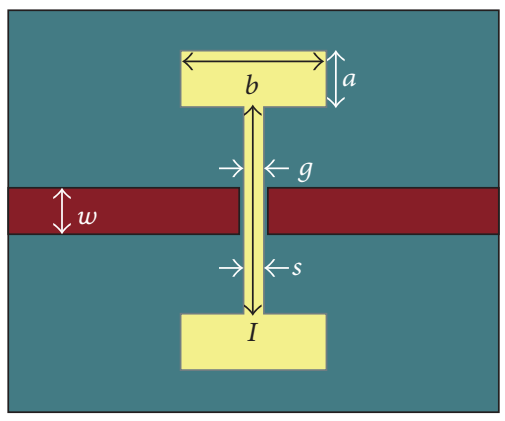

(a)

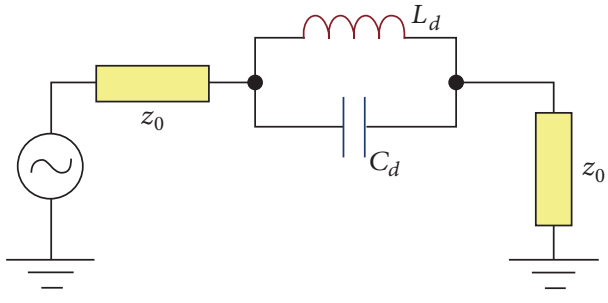

(b)

FIGURE 4: The physical structure (a) and the equivalent circuit (b) of dumbbell DGS.

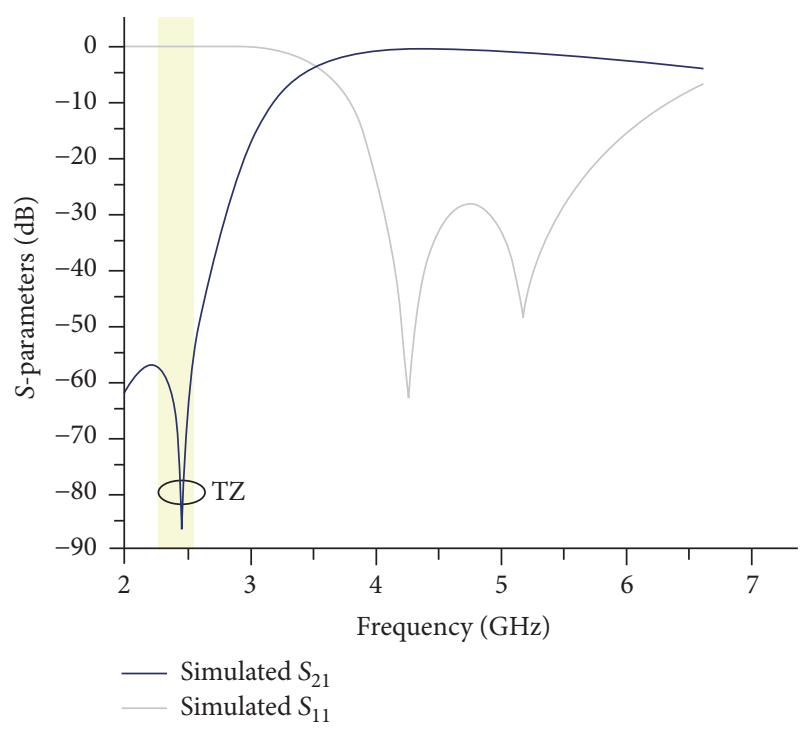

FIGURE 5: The simulated $S$-parameters of the dumbbell DGS.

In order to implement the proposed filter, firstly, the resonant frequency of the passband produced by the CSRRs based on the evanescent mode below the cutoff frequency of the SIW is calculated and designed. The second step is to add a pair of dumbbell DGSs at each side of the CSRRs to create an extra transmission zero which can increase out-of-band rejection. For CSSRs, they behave like composite right/lefthanded resonators, which can generate the evanescent mode of the SIW cavity. This evanescent resonance is the negative resonant mode of the CSSRs, where the electric field, the magnetic field, and the propagation vector satisfy the lefthanded rule, which is contrary to the traditional resonant mode where only right-handed rule can be satisfied. Hshaped DGSs are placed near the input and output feed lines. They work as a pair of "gates" which block the transmission of electromagnetic wave at certain frequencies; thus, transmission zeros can be generated consciously. At the frequencies where DGSs act as microwave bandgap structures, electromagnetic energy is radiated to free space through the two h-shaped DGSs. Therefore, the isolation between the passbands can be improved. And in this way, of course, DGSs and CSRRs are not completely independent. The influence between DGSs and CSRRs cannot be neglected due to parasitic effects as well as the weak coupling, and therefore the next step is to tune and make optimizations using EM simulation software. After satisfactory results have been achieved, the final step is fabrication and measurement to verify the correctness of simulation results.

\section{Simulation and Measurement}

The topology of the proposed filter is shown in Figure 6. The CSRRs are placed in the center of the SIW cavity to create the passbands in the frequency response. Two dumbbell DGSs 


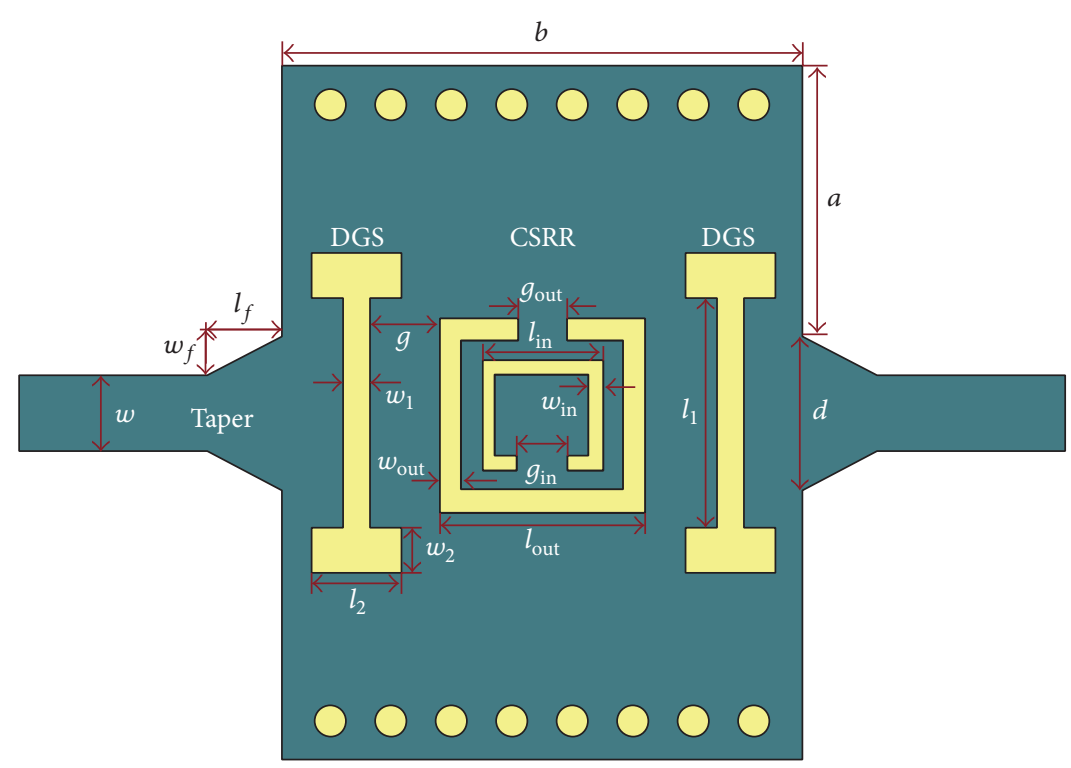

FIGURE 6: The topology of the proposed filter.

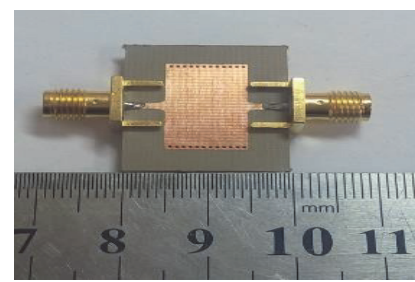

(a)

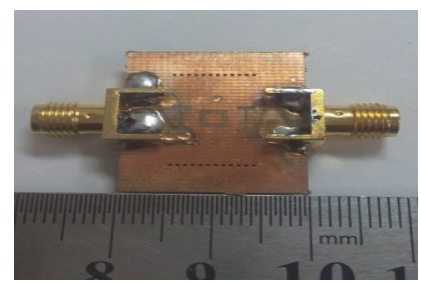

(b)

FIgURE 7: The top view (a) and the bottom view (b) of the fabricated filter.

are placed at each side of the CSRRs to produce an extra transmission zero which can increase the isolation between these two passbands. The input and output ports are microstrip feed lines with characteristic impedance of $50 \mathrm{ohm}$. In order to increase the effectiveness of electrical feeding, a pair of tapers function as transition of the transmission line is added between the microstrip line and the SIW.

The filter is fabricated on the Taconic RF-35 substrate with the thickness of $0.508 \mathrm{~mm}$, relative dielectric constant of 3.50, and loss tangent of 0.0018, as shown in Figure 7. The geometric parameters of the filter are tabulated in Table 1. The filter is simulated using the EM full wave simulation software HFSS and measured using the vector network analyzer ZVA40 of the Rohde \& Schwarz company. The simulated and measured results are depicted in Figure 8. Two passbands have been created within the frequency range from $2 \mathrm{GHz}$ to $14 \mathrm{GHz}$. The first passband works at the evanescent mode below the cutoff frequency of the SIW. Its center frequency is $5.4 \mathrm{GHz}$ with the insertion loss of $1.1 \mathrm{~dB}$ and the relative $3 \mathrm{~dB}$ bandwidth of $17.2 \%$. The second passband works at $\mathrm{TE}_{101}$ resonant mode. Its center frequency is $10.1 \mathrm{GHz}$ with the relative $3 \mathrm{~dB}$ bandwidth of $55.2 \%$. These two passbands work at different resonant modes, and the bandwidth of the second passband is much wider than that of the first one. A transmission zero is produced at $6.9 \mathrm{GHz}$
TABLE 1: The geometric parameters of the proposed filter ( $\mathrm{mm})$.

\begin{tabular}{lc}
\hline Parameter & Value $(\mathrm{mm})$ \\
\hline$a$ & 7.5 \\
$l_{\text {in }}$ & 2.2 \\
$l_{\text {out }}$ & 3.0 \\
$g_{\text {in }}$ & 0.4 \\
$l_{1}$ & 3.5 \\
$l_{2}$ & 2.0 \\
$w$ & 1.2 \\
$l_{f}$ & 0.8 \\
$g$ & 1.8 \\
$b$ & 10.0 \\
$w_{\text {in }}$ & 0.2 \\
$w_{\text {out }}$ & 0.2 \\
$g_{\text {out }}$ & 0.4 \\
$w_{1}$ & 0.2 \\
$w_{2}$ & 0.5 \\
$w_{f}$ & 0.4 \\
$d$ & 2.0 \\
\hline
\end{tabular}

with the measured rejection level of $27.2 \mathrm{~dB}$. It can be found that the measured results are in good agreement with the 
TABLE 2: Performance comparisons with other recent published SIW filters.

\begin{tabular}{lcccc}
\hline Reference & Center frequencies of the passbands $(\mathrm{GHz})$ & $3 \mathrm{~dB}$ fractional bandwidth $(\%)$ & Insertion loss $(\mathrm{dB})$ & $2.2 / 2$ \\
\hline$[11]$ & $5.85 / 6.15$ & $1.3 / 1.3$ & $1.8 / 1.94$ & $2.11 \lambda_{0} \times 2.11 \lambda_{0}$ \\
{$[12]$} & $5.3 / 8.7$ & $6.8 / 3.2$ & $1.2 / 1.3$ & $1.38 \lambda_{0} \times 0.73 \lambda_{0}$ \\
{$[13]$} & $4.8 / 5.4$ & $3.8 / 3.9$ & $2.24 / 2.01$ & $2.67 \lambda_{0} \times 2.64 \lambda_{0}$ \\
{$[14]$} & $9.4 / 9.98$ & $3.1 / 3.7$ & $1.1 / 1.4$ & $0.59 \lambda_{0} \times 0.51 \lambda_{0}$ \\
This work & $5.4 / 10.1$ & $17.2 / 55.2$ &
\end{tabular}

$\lambda_{0}$ is the guided wavelength at the center frequency of the first passband.

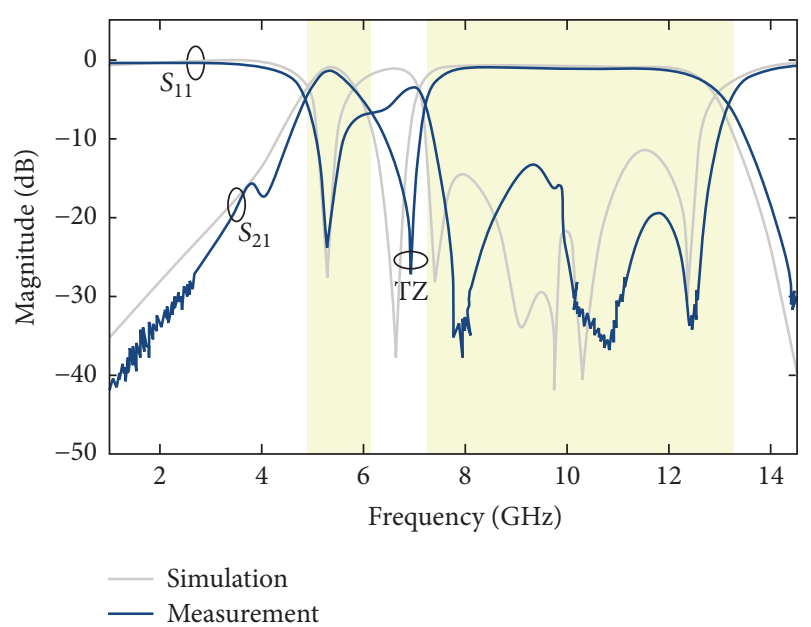

Figure 8: The simulated and measured results.

simulated results and the discrepancies are mainly due to the uncertainty of fabrication. The performance comparisons with other recent published SIW filters are given in Table 2. The advantages the proposed filter are quite obvious. Much wider $3 \mathrm{~dB}$ fractional bandwidth has been achieved and the size of the filter is very compact, also the insertion loss is acceptable.

\section{Conclusion}

In this paper, a novel SIW bandpass filter using CSRRs with DGSs has been presented and analyzed. Three different structures are combined together to implement the proposed filter. Two passbands are created by evanescent mode and $\mathrm{TE}_{101}$ mode. The rejection level between the passbands is improved due to the transmission zero generated by DGSs. The measured results are in good agreement with the simulation results, and, by comparing with other similar filters, the proposed filter has the advantages of much compact size, lower insertion loss, and wider $3 \mathrm{~dB}$ fraction bandwidth, which makes it feasible and applicable in modern microwave communication circuits.

\section{Competing Interests}

The authors declare that there is no conflict of interests regarding the publication of this paper.

\section{Acknowledgments}

The work is supported by National Natural Science Foundation of China (no. 61563015), Young Foundation of Humanities and Social Sciences of Ministry of Education in China (no. 13YJCZH089), and Young Foundation of Educational Commission of Jiangxi Province of China (no. GJJ14401).

\section{References}

[1] D. Deslandes and K. Wu, "Single-substrate integration technique of planar circuits and waveguide filters," IEEE Transactions on Microwave Theory and Techniques, vol. 51, no. 2, pp. 593-596, 2003.

[2] X.-P. Chen and K. Wu, "Substrate integrated waveguide filters: design techniques and structure innovations," IEEE Microwave Magazine, vol. 15, no. 6, pp. 121-133, 2014.

[3] P. Li, H. Chu, and R. S. Chen, "SIW magic-T with bandpass response," Electronics Letters, vol. 51, no. 14, pp. 1078-1080, 2015.

[4] M. Esmaeili and J. Bornemann, "Substrate integrated waveguide dual-stopband filter," Microwave and Optical Technology Letters, vol. 56, no. 7, pp. 1561-1563, 2014.

[5] J. D. Baena, J. Bonache, F. Martín et al., "Equivalent-circuit models for split-ring resonators and complementary splitring resonators coupled to planar transmission lines," IEEE Transactions on Microwave Theory and Techniques, vol. 53, no. 4, pp. 1451-1460, 2005.

[6] J. Esteban, C. Camacho-Peñalosa, J. E. Page, T. M. MartínGuerrero, and E. Márquez-Segura, "Simulation of negative permittivity and negative permeability by means of evanescent waveguide modes-theory and experiment," IEEE Transactions on Microwave Theory and Techniques, vol. 53, no. 4, pp. 15061513, 2005.

[7] Y. H. Song, G.-M. Yang, and W. Geyi, "Compact UWB bandpass filter with dual notched bands using defected ground structures," IEEE Microwave and Wireless Components Letters, vol. 24, no. 4, pp. 230-232, 2014.

[8] S. Biswas, D. Guha, and C. Kumar, "Control of higher harmonics and their radiations in microstrip antennas using compact defected ground structures," IEEE Transactions on Antennas and Propagation, vol. 61, no. 6, pp. 3349-3353, 2013.

[9] D. Suhas, C. R. Lakshmi, Z. S. Rao, and D. Kannadassan, "A systematic implementation of elliptic low-pass filters using defected ground structures," Journal of Electromagnetic Waves and Applications, vol. 29, no. 15, pp. 2014-2026, 2015.

[10] Y. L. Zhang, W. Hong, K. Wu, J. X. Chen, and H. J. Tang, "Novel substrate integrated waveguide cavity filter with defected ground structure," IEEE Transactions on Microwave Theory and Techniques, vol. 53, no. 4, pp. 1280-1286, 2005. 
[11] M. Rezaee and A. R. Attari, "A novel dual mode dual band SIW filter," in Proceedings of the 44th European Microwave Conference (EuMC '14), pp. 853-856, Rome, Italy, October 2014.

[12] Y.-D. Wu, G.-H. Li, W. Yang, and T. Mou, "A novel dual-band SIW filter with high selectivity," Progress in Electromagnetics Research Letters, vol. 60, pp. 81-88, 2016.

[13] H. Wsx and Y. Wu, "Compact SIW dual-band bandpass filter using novel dual-resonance quasi-SIW-transmission-linestructure resonators," The Journal of Engineering, 2016.

[14] G. Zhang, J. Wang, S. Ge, and W. Wu, "A new balanced dualband SIW bandpass filter with high common-mode suppression," in Proceedings of the Asia Pacific Microwave Conference (APMC '16), New Delhi, India, February 2016. 


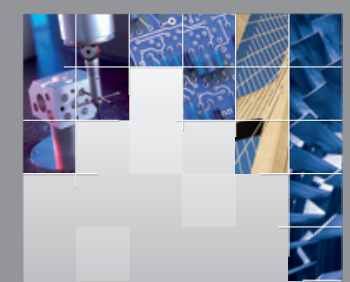

\section{Enfincering}
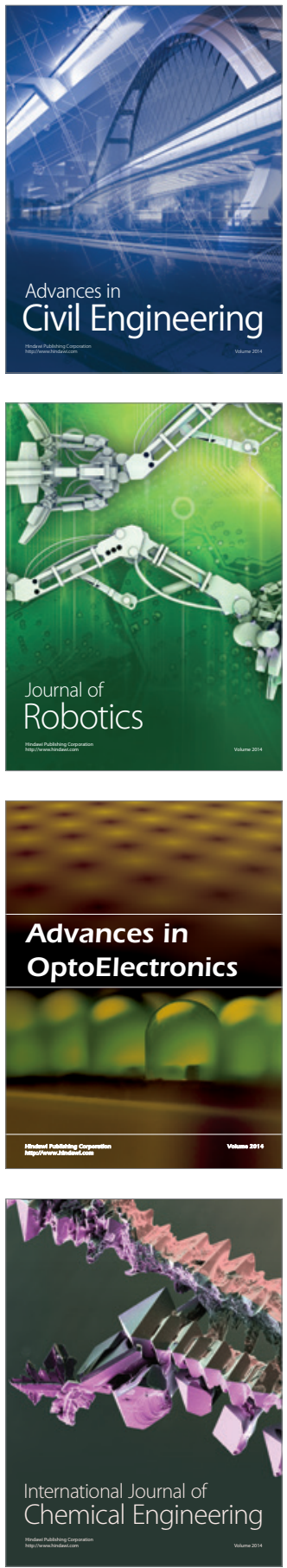

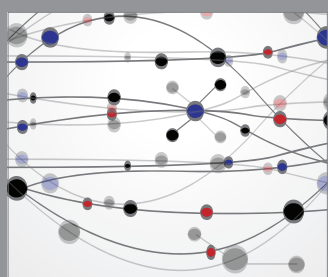

The Scientific World Journal

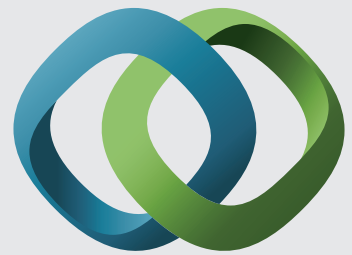

\section{Hindawi}

Submit your manuscripts at

https://www.hindawi.com
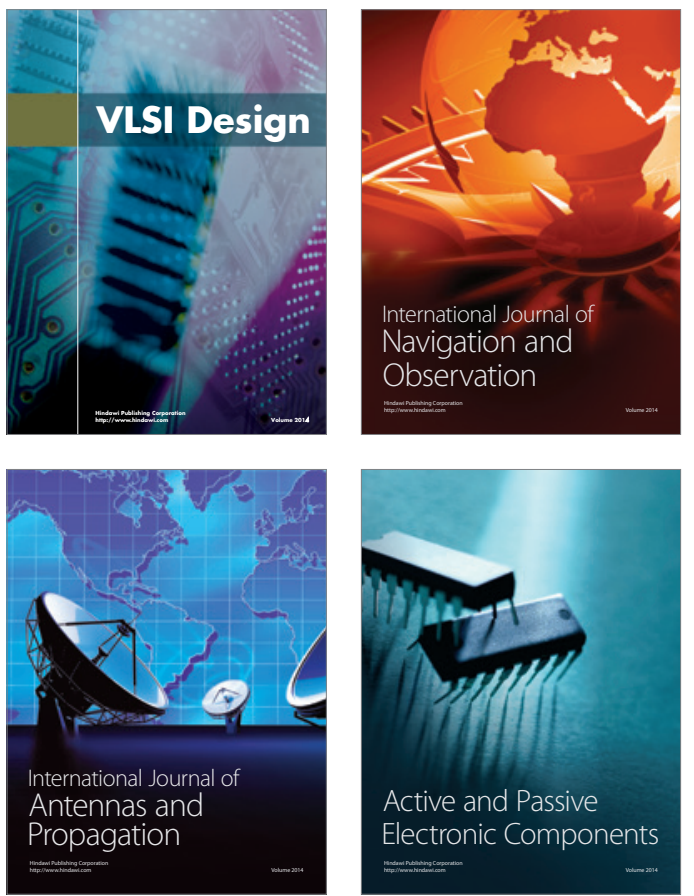
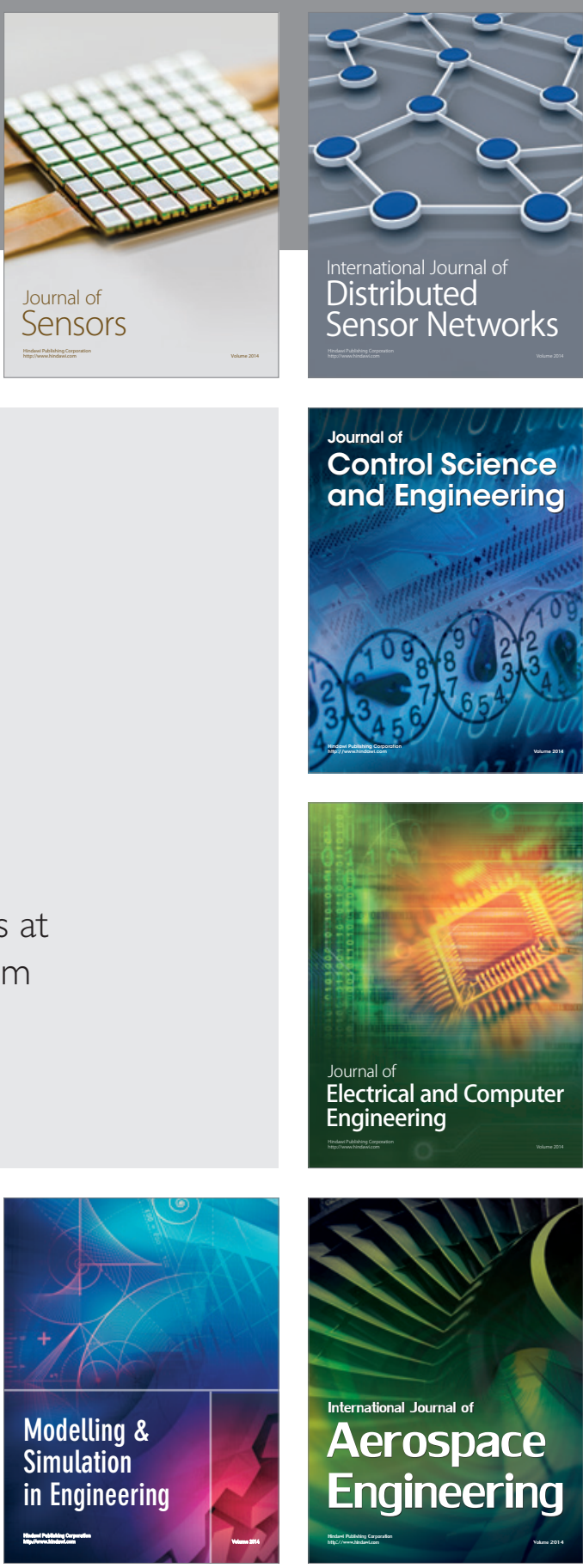

International Journal of

Distributed

Sensor Networks

$-$

Joumal of

Control Science

and Engineering
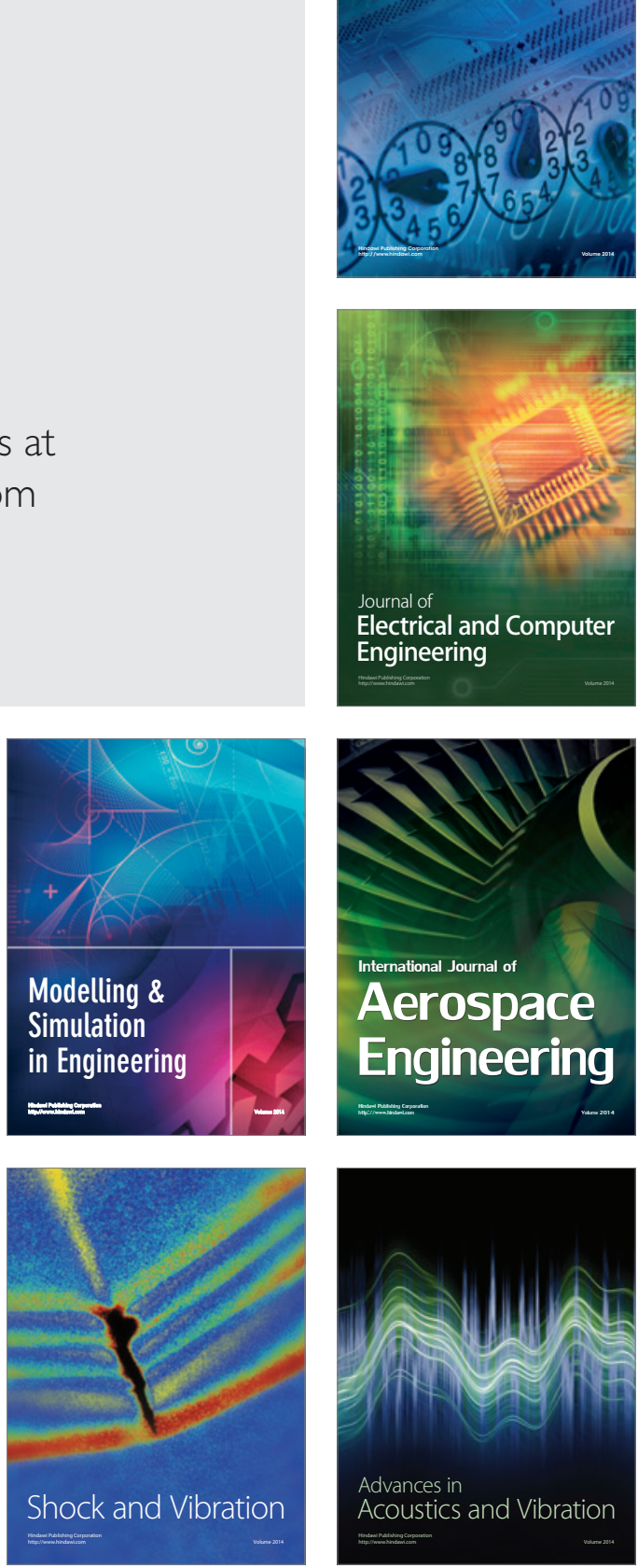